\title{
Framing of Arab Conflicts in India by the Leading Private News Channels NDTV 24*7 and CNN-IBN
}

\author{
Sweta Singh \\ University School of Mass Communication, Guru Gobind Singh Indraprastha University, New Delhi, India \\ Email: swetasingh2000@gmail.com
}

How to cite this paper: Singh, S. (2018). Framing of Arab Conflicts in India by the Leading Private News Channels NDTV $24^{\star} 7$ and CNN-IBN. Advances in Journalism and Communication, 6, 27-37. https://doi.org/10.4236/ajc.2018.62003

Received: February 15, 2018

Accepted: April 5, 2018

Published: April 8, 2018

Copyright $\odot 2018$ by author and Scientific Research Publishing Inc. This work is licensed under the Creative Commons Attribution International License (CC BY 4.0).

http://creativecommons.org/licenses/by/4.0/

\section{(c) (i) Open Access}

\begin{abstract}
During Arab "Spring", two broad frames emerged from the coverages by Indian news television: Western and regional. The former caters to the West for its primary viewership whereas the latter is an alternative to CNN for the Arab region. During the conflicts, Indian news television catered to the dominant western perspective due to feeds from western news agencies. So when the Arab Conflicts got mediated to India, a non-participating zone, then it was only likely that the western perspective would dominate the audio-visual narratives because of continued dependency on the western news agencies as has been demonstrated earlier conflicts like invasions of Iraq and Afghanistan. Through a qualitative framing analysis, this research looks at how Arab Conflicts got mediated by NDTV and CNN-IBN, the two leading private English news channels. An analysis of news packages by the two channels during the year 2011 with respect to framing of issues, stakeholders and sources reveals a stronger presence of western perspective in the audio-visual narratives in spite of the fact that channels correspondents contributed almost the same number of stories as those from the western sources.
\end{abstract}

\section{Keywords}

Framing, Arab Spring, Conflict, Private Television, India, NDTV, CNN-IBN

\section{Introduction}

Arab Conflicts, came to be known as Arab "Spring" in many parts of the world including India. The phrase Arab "Spring" which was coined in the West, got recycled without questioning, like many other phrases that evolved during the conflicts in West Asia and North Africa that started in December 2010. The In- 
dian media not only borrowed the phrase, it recirculated it to the domestic viewers as if it was a universal phrase. The phrase stands for the developments that supposedly started with the death of a young man in Tunisia and within days, spread to most of the Arab world. Encyclopaedia Britannica defines Arab "Spring" as a wave of pro-democracy protests and uprisings that took place in the "Middle East" and North Africa beginning in 2010 and 2011, challenging some of the region's entrenched authoritarian regimes (Arab Spring, 2015; “Arab Spring: Pro-democracy protests", 2014) Sadiki (2016) quotes Whitehead and adds that the phrase Arab "Spring" gained currency after its use in an article by Marc Lynch (2011), a week before Bin Ali of Tunisia agreed to step down. The BBC Trust analysis (A BBC Trust report on the impartiality and accuracy of the BBC's coverage of the events known as the "Arab Spring", 2012: p. 16) have suggested that the phrase Arab "Spring" is misleading and gives wrong impression of what actually happened through a pre-conceived lens. Madanjeet Singh, founder of the South Asian Foundation and former UNESCO Goodwill ambassador, writes in The Hindu (Singh, 2011):

"Arab Spring is a misnomer used by the media to describe the uprising that the self-immo-lation of Mohammad Bouazizi unleashed in Tunisia on December 18, 2010 in protest against corruption and ill-treatment-a spark that ignited into wildfire and spread to Algeria, Jordan, Egypt, Yemen, and other countries".

The "peoples" uprisings calling for the change in regime marked by protests and intervention by US and North Atlantic Treaty Organisation (NATO) received immense media coverage globally. Indian news media followed suit and covered the developments as they were taking place in its neighbourhood.

The shrinking space of foreign news in Indian media has been a cause concern. The scenario is even more dismal when it comes to private television news channels that have become the dominant influencers of public opinion (Malik, 2005). The space for foreign news gets even more limited as most of the private television channels tend to be driven by concerns for ratings and hence tend to focus on domestic news to meet the requirements of the advertisers. Vardhan (2017) writes:

"This is ironic when you consider that for a decade now, the buzz, or even India's self-per ception, has been about the country being one of the rising global powers. Indian media doesn't reflect that global aspiration in its news lists since it can hardly claim to be your window to the world beyond India."

In such a scenario, it is worth asking as to why some foreign conflicts become newsworthy for the news television in India and how do they get treated. This research argues that the private channels framed the stories from western ideological lens.

The study begins by reviewing the relevant literature on how various scholars have studied the coverage of Arab Conflicts. It later reviews the works done on framing analysis and news as frame. The literature also looks at the Indian media's engagement with foreign news and Arab Conflicts to put the central idea of 
the research in perspective. The literature review is followed by the two research questions asked. The method details follow where the researcher provides the research design and the tools used for the study. In this case, exploratory research design has been used for qualitative content analysis using framing as a tool to study the audio-visual cues. The key constructs of issues, stakeholders and sources have been defined eventually. The findings and conclusion of the study are presented later in the research.

\section{Literature Review}

Coverage of Arab Conflicts has multiple dimensions and the scholars have attempted to look at those dimensions differently. A good number of these have to do with how the US and western media covered them (BBC Trust Report, 2012; Dube, 2013; Guzman, 2015). Other studies point at how the Arab media covered the events. And some have attempted a comparison of coverage by Arab and the US media (Alalawi, 2015). Very few studies look at how a the media of a non-participating country covered these conflicts and the dominant narratives that emerged from these coverages (Alam, 2015). In India, as in the past during Gulf War and subsequent invasions of Iraq and Afghanistan, it has been observed that the coverage show western perspectives. Many scholars have studied the dimension of international news media and its role in coverage of Arab Uprisings where the researcher studies how western media has shaped political understandings in the affected countries. Other literature studying the framing of Arab Conflictshave looked at how the stakeholders like Muslim Brotherhood and protesters were framed (Straaten, 2013).

Prior to this, a similar trajectory of studies has been explored especially after the expansion of CNN as "global television" network during Iraq War in 1991 (Lee, Maslog, \& Kim, 2006; Luke \& Tuathail, 1997). Baudrillard (1995) explores how broadcasting changed in many parts of the World with the direct satellite broadcasting of news by CNN during the Gulf War. It also weighs the impact of this change on coverage of international conflicts. He adds that an important event in global broadcasting of news ushered a whole lot of changes wherever $\mathrm{CNN}$ had a footfall spelling huge shifts in the way conflicts have been telecast before. Many of these scholars have explored the coverage primarily in the context of the Arab world or the United States and the West. There is very little literature exploring the dimension of a non-participant country's perspective, a distant but important stakeholder like India during such conflicts. Bidwai (2003) writes:

Regrettably, there aren't too many Indian channels which use Al-Jazeera or Abu Dhabi TV as feed. However, the state-owned Doordarshan channel, with the widest coverage of all, has been carrying brief bulletins by an Indian programming company, Third Eye TV. This provides independent and far more critical spot coverage of the events in Iraq. (Bidwai, 2003)

Barrett (2011) argued about the Indian mediascape in the wake of expanding 
foreign television network and internet. He refers to the New World Information and Communication Order (NWICO) debates of 1970s when the global domination of four western news agencies was seen as a form of information imperialism. He argues that in this market-led development, there has been further deterioration in the relations of power. This imbalance in information and communication flow was aimed to be overcome as reflected from the MacBride commission report and its recommendations.

Kumar (2011) argues that Gramscian hegemony and not overt imperialism characterises contemporary media and the paradigm shift due to technological convergence and digitisation has collapsed to serve monopolies. Though Kumar talks about the digital mediascape, the arguments hold true for even the conventional news television.

Talking about conflicts, Thussu and Freedman argue that the mainstream media has been identified as the battleground, the surface upon which war is imagined and executed (Thussu \& Freedman 2005). They assign two other narratives regarding the role of mainstream media in communicating conflict. They see media as critical observer and publicist. They quote Robert McChesney, John Nicolas and Noam Chomsky who argue that an increasingly market-led media largely ignores dissenting voices in favour of corporate and government tunes. To this, one can add that when it comes to coverage of international conflicts, the news television follows the narratives provided by the western news agencies and foreign news channel.

Anwar Alam (2015) states that during Arab Uprisings, there were lively debates in Indian media. And they welcomed fall of dictatorial governments. But this literature does not give details about the framing of Arab Uprisings especially by television news channels in India.

To a greater extent, Indian news television churned out the packaged narratives of the Western media, even those that narrated about democracy being the best alternative in the Arab World. For instance the Indian media failed to engage the viewers on western governments' policy of Arab exceptionalism or intervention of NATO in Libya in the conflicts.

To study this rather unexplored dimension of how news television covered international conflict, Arab Conflictsin this case, this research looks at the framing analysis approach. Several scholars have studied the dependence of Indian viewers on mainstream news television for their information about far away regions and their conflicts. And how the news organisations frame news stories in the process of packaging the information have also been explored. Framing theory suggests how something is presented to the audience, through the frame. Framing in turn influences the choices people make about how to process that information (Asemah \& Edegoh, 2012). Framing has been defined as the ways in which representations functions to re-contexualise (and thus change meaning of) that which they represent. Goffman (1974, p. 24) states that audience tend to perceive events in terms of primary frameworks and the type of frame which we employ provides a way of describing the event to which it is applied. Tuchman 
(1978, p. 1) writes that "news is a window on the world and through its frame, Americans (public) learn of themselves and others, of their institutions, leaders and lifestyles and those of other nations and other people's. The news, need to know, and should know. But, like any frame that delineates the world, a news frame may be problematic. The view through a window depends upon whether the window is large or small, has many panes or few whether the glass is opaque or clear, whether the window faces a street or a backyard". Thus the news media have the power to shape news consumers' opinions and topics about which they are ignorant.

Gamson and Modigliani define frame as a "central organising idea for making sense of relevant events, suggesting what is at issue" and Gitlin (1980, p. 6; 1989) identifies frames as principles of selection, emphasis, and presentation composed of little tacit theories about what exists, what happens, and what matters. Accordingly, media frames are persistent patterns of cognition, interpretation, and presentation of selection, emphasis and exclusion, by which symbol-handlers routinely organise discourse, whether verbal or visual (p. 7).

Episodic and thematic frames have been defined by Iyengar and Simon (1993), wherein episodic frames refer to coverage of events and issues in terms of "specific events", focusing on on-the-scene coverage of particular people and events. Whereas thematic framing opts for a more general presentation of events that takes into consideration the wider context, background and follow-ups of covered events (p. 370). According to Iyengar and Simon (1993), the media coverage of conflicts in the West Asia was exposed to episodic framing which increased public support for U.S. military intervention to resolve the conflict.

Entman (1993, p. 52) identifies framing as a process that essentially involves selection and salience. To frame is to select some aspects of a perceived reality and make them more salient in the communicating text, in such a way as to promote a particular problem definition, causal interpretation, moral evaluation, and/or or treatment recommendation for the item described. Frame analysis serves the following purposes within the context of media research: to define problems, to diagnose courses, to make value judgements and to suggest remedies.

\section{Research Questions}

R1: How were the themes, issues and stakeholders framed by the two news channels?

R2: What were the sources "of" and "in" the stories?

\section{Method}

Exploratory research design has been used to analyse the audio-visual narratives on the two news channels. An exploratory design is conducted about a research problem when there are few or no earlier studies to refer to or rely upon to predict an outcome. The focus is on gaining insights and familiarity for later investigations undertaken when research problems are in a preliminary stage of in- 
vestigation. Exploratory designs are often used to establish an understanding of how best to proceed in studying an issue or what methodology would effectively apply to gathering information. This research incorporates qualitative content analysis using framing tool. Framing analysis is useful for scrutinising discourse structures adopted by journalists. This analytical tool reveals the probable frames that may reflect on the location of the stories, the actors in the narratives, and the voices represented.

The data was sampled purposefully from the websites of NDTV and CNN-IBN. Individual news packages related to conflicts in Egypt and Libya were used as units of analysis. Two hundred and five news packages were coded by single coder using a code sheet and the categories were operationalised. To answer the research questions, the content categories were identified. Issues like "regime change", "violence", "protests", "Indians in conflict", "deaths" and "democracy" were studied. These issues were conceived based on a pilot study done on a smaller sample which showed that these issues dominated the stories on Arab Conflicts. All the available stories from the websites and youtube channels posted in 2011 were analysed. The keywords used for searching news packages included "Arab Spring”, "Arab Uprising/s", "Egypt", "Libya", "Tunisia", "Bahrain", and "Yemen".

\subsection{Issues}

These are the basic ideas that dominated much of the discourse around Arab Conflicts. They were the reasons for which the conflicts took place. The issues have been categorised as poverty and unemployment, corruption, protests, violence, democracy, oil, geo-politics and the NATO interventions.

\subsection{Stakeholders}

They were identified as Mubarak, Gaddafi, Army, Protestors, India and NATO.The qualitative analysis looked at the way the five stakeholders got framed through choice of words, phrases and audio-visual representation.

\subsection{Sources}

The sources were divided into two categories: source "of" the stories and source "in" the stories. Source "of" the story are originating news organisations from where the audio-visuals arrived in the news room that were used in the news packages. In this study the sources are the foreign news agencies, foreign channels and channels own correspondents. These are the senders of the news stories. Sources "in" the stories included those who are speaking in the stories. They have been categories as sound bites of locals, foreigners, government, channel's correspondents and foreign correspondents. The sources "in" are the individuals who are part of the story and facilitate the narration of the news story. They were studied by looking at the volume of coverage, the words and phrases used and the story support. 


\section{Findings and Discussions}

The qualitative analysis of data reveals a strong dependency of the news channels on foreign sources or the western news agencies/channels/correspondents. This dependency's was more for CNN-IBN due to its origins rooted in CNN. There was frequent use of stories from CNN, the international channel. Sometimes their correspondents and experts were also used in the news packages. This connect of CNN-IBN with CNN aligned the narratives towards the one directed by the originating channel-CNN. Though the correspondents did visit the "ground zero" but bulk of the stories were based on CNN's footages and those provided by the western news agencies. There was no visibility of alternative news networks like Al Jazeera and Al Arabia. NDTV managed to send two correspondents on the ground that added closer perspective for India.

At this point, applying the framing analysis, the data shows that the issues of regime change, protests, violence, Indians in conflict, deaths and democracy dominated along with others that received minor attention like human rights, unemployment, social media and corruption. These were framed in accordance with the western perspective, borrowed from the agencies as reflected from the choices of words and phrases as well as the story support. The audio-visual narratives had little scope for change except for minor tweaking of the voice-over which was mostly done in-house by the news channels. They were framed to create an antipathy for the rulers and their style of governance, a narrative that was needed by the West for its own geo-political interest. The narratives seemed to encourage people to take to streets, not to give-up and overthrow the existing regimes at any cost.

As far a the representation of stakeholders are concerned, the rhetorical use of words like "defy" and "brave" for protesters, "buckle", "struggle", "authoritarian", "dictator", "power", "corrupt" for Mubarak and Egyptian government show that the protesters were framed as legitimate while Mubarak and his government were shown as "stubborn". Protesters were shown friendly with the Army in Egypt. In Libya, Gaddafi was depicted as the "mad dog", "dictator", "brutal", "corrupt", "religious fanatic" "evil", amongst others. West was shown as reactive and not pro-active stakeholder, that was not interested so much in the geo-political gains out of the regime changes happening in the region, but furthering universal values of democracy and peace. Its leaders were shown siding with the protesters, justifying the conflicts in the name of democracy. They sounded supportive of the regime change in the region in the name of "will of the people".

Democracy was frequently used in most of the stories to connect with the protesters both in Egypt and Libya. In fact, the leaders' pasts were tracked as "dictatorial" and "authoritative", hence "bad", "evil" and "ought to be replaced by democratic alternatives". This was articulated by NATO leaders at different points. Democracy was played out to be the way to go forward as reflected from the sound bites collected by the foreign sources. Sound bites suggest that the 
pretext of democracy was used to side with protesters in Egypt and rebels in Libya, oversimplifying the complex war narratives.

The foreign sources covered almost the same amount of stories as those by the channels' correspondents. There were stories where it was not possible to identify the news sources as they were read over by the anchors. This dependence on foreign agencies and foreign sources led the Indian channels to give primacy to western ideologies and perspectives while defining success and failures of the protests. It also made the narrative of Arab Conflicts appear as a regional problem.

The sources "in" the stories did not attempt to name the individuals and groups like NATO and the larger geo-political interests like "oil politics", overtly or covertly causing these protests. The use of binaries emerged in the narratives as "good protesters" fighting against "bad regimes".

There was little or no background information about how the relations between the West and the WANA region changed leading to such conflicts. The treatment of important issues remained episodic, much to the advantage of US and NATO countries. The phrase "winds of change" for Libyan protests show the subtle intent where protests are justified especially in the stories coming from foreign sources. There are stories which describe and are not critical of what US thinks and wants.

The visuals, mostly located on the streets and in the war zones are replete with large scale violence. The deaths are inadequately counted. The visual framing of violence long shots miss the closer stories. The scale of loss of life and culture are not narrated either through audio or through the visuals. Seldom do we see dead bodies. While civilians deaths were not visible, the "lynching" of Gaddafi and display of his dead body were exhibited more on CNN-IBN. In many ways it seemed like a sanitised war where we see weapons, ammunitions, tanks, protesters clashing but we do not see those killed, orphaned and turned homeless. This "invisible" approach to conflicts gives salience to military intervention by the West as seen in Libya. There weren't many stories that depicted the futility of war. In fact, the larger narratives that emerged from the conflict zone made the conflict look as an internal matter of the countries and to an extent, justified. In Libya, there was intervention of NATO but that was not questioned or covered through visuals by the foreign sources. The local correspondents from both the channels tried to add the missing perspectives by questioning foreign intervention but those remarks remained on the fringes.

India appeared to be reluctant participant or neutral observer. There were delayed and short comments from the government. There were a few detailed interviews with the Indian embassy officials in Cairo and Tripoli. Indians were seen mostly as migrant workers around dockyards or those employed as nurses, engineers with technology firms or working for business firms getting rescued and landing at airport to tell their stories. While the former group was visible in dockyards from Egyptian and Libyan shores, the latter was visible arriving at Mumbai airport. The arrival stories were covered by channels own correspon- 
dents. India's role in this shifting geo-politics that shaped these protests did not come out with adequate clarity and context as shown by the volume of issues covered and sources "in" the stories.

\section{Conclusions}

The study shows that the two private news channels - CNN-IBN and NDTV 24 $\times 7$ added to the overall volume of discourse on Arab Conflicts in the year 2011 for the Indian viewers. The availability of the channels' correspondents for a limited duration on ground zero constructed lengthier audio-visual narratives but they lacked background information and context for viewers in this part of the world. Due to this, the homogeneous narratives of the West sourced from the foreign agencies were repackaged and aired for the domestic viewers. In the process, they seem to have extended the borrowed narratives of foreign sources through choice of words, phrases, visuals and their treatment. The audio-visual cues also indicate that the stakeholders like "Mubarak" and "Gaddaffi" were portrayed as negative individuals in the binary that evolved to represent protesters and NATO as positive entities.

India featured as a distant stakeholder depicted through rescue and evacuation efforts by the Government and some very easily available and predictable stories from the airports taken on arrival of Indians. India's geo-political stand did not evolve adequately due to absence of official sources "in" the stories.

The channels succeeded in making Arab Conflicts visible to the Indian viewers but they missed the opportunity to critically engage them through alternative narratives and could not stand in the wake of dominant narratives of the West.

This study has some limitations as well. The data was collected from the websites and the Youtube channels. The sample data is thus limited and needs to be explored by examining the televised stories in a linear fashion to look at other variables like follow-up coverage in further research to get a more precise sense of the coverages.

Also, the news scripts were transcribed from the web content due to which the transcripts may not be exactly the same as those aired on televisions.

The research studies only Egypt and Libya. Other countries representation may be explored in further studies to get a holistic understanding of coverages on Arab Conflicts.

\section{References}

Alalawi, N. (2015). How Media Covered “Arab Spring” Movement: Comparison between the American Fox News and the Middle Eastern Al Jazeera. Journal of Mass Communication \& Journalism, 5, 281. https://doi.org/10.4172/2165-7912.1000281

Alam, A. (2015). Arab Spring: A View from India. In Routledge Handbook of the Arab Spring: Rethinking Democratization (1st ed., pp. 636-649). Routledge.

Arab Spring. The Editors of Encyclopædia Britannica (2015). Arab Spring. http://www.britannica.com/event/Arab-Spring

Asemah, E. S., \& Edegoh, L. O. (2012). Mass Media Agenda and Conflict Resolution in 
Jos, Plateau State, Nigeria. An International Journal of Arts and Humanities, 112-129. Retrieved from Mass Media Agenda and Conflict Resolution in Jos, Plateau State, Nigeria.

Barrett, O. B. (2011). Rethinking News Agencies, National Development and Information Imperialism.

http://www.epw.in/journal/2011/13/reflections-empire-special-issues-specials/rethinki $\underline{\text { ng-news-agencies-national }}$

Baudrillard, J. (1995). The Gulf War Did Not Take Place. Indian University Press.

BBC Trust (2012). Report on BBC Coverage of "The Arab Spring".

https://www.scribd.com/document/115669497/Report-on-BBC-coverage-of-The-Arab-S pring-BBC-Trust

Bidwai, P. (2003). Revulsion, Disgust in India at the War. http://www.antiwar.com/bidwai/bi032903.html

Dube, J. (2013). International News Media Coverage of the "Arab Spring": Actors, Technology and Political Impacts. http://digitalcommons.auctr.edu/dissertations/1285/

Entman, R. M. (1993). Framing: Toward Clarification of a Fractured Paradigm. Journal of Communication, 43, 51-58. https://doi.org/10.1111/j.1460-2466.1993.tb01304.x

Gamson, W. A., \& Modigliani, A. (1989). The Changing Culture of Affirmative Action. Research in Political Sociology, 3, 137-177.

Gitlin, T. (1980). The Whole World Is Watching: Mass Media in the Making and Unmaking of the New Left. Berkelry: University of California Press.

Goffman, E. (1974). Frame Analysis: An Essay on the Organization of Experience. New York, NY: Harper \& Row.

Guzman, A. L. (2015). Evolution of News Frames during the 2011 Egyptian Revolution. Journalism \& Mass Communication Quarterly, 93, 80-98. https://doi.org/10.1177/1077699015606677

Iyengar, S., \& Simon, A. (1993). News Coverage of the Gulf Crisis and Public Opinion: A Study of Agenda-Setting, Priming and Framing. Communication Research, 20, 365-383. https://doi.org/10.1177/009365093020003002

Kumar, S. (2011). Hegemony in Contemporary Culture and Media and the Need for a Counter Initiative.

http://www.epw.in/journal/2011/51/perspectives/hegemony-contemporary-culture-and$\underline{\text { media-and-need-counter-initiative }}$

Lee, S. T., Maslog, C. C., \& Kim, H. S. (2006). Asian Conflicts and the Iraq War. International Communication Gazette, 68, 499-518. https://doi.org/10.1177/1748048506068727

Luke, T. W., \& Tuathail, G. Ó. (1997). On Videocameralistics: The Geopolitics of Failed States, the CNN International and (UN) Governmentality. Review of International Political Economy, 4, 709-733. https://doi.org/10.1080/09672299708565789

Malik, A. (2005). Media Coverage of Foreign Affairs Part I. http://www.thehoot.org/research/books/media-coverage-of-foreign-affairs-part-i-1477

Sadiki, L. (2016). Routledge Handbook of the Arab Spring: Rethinking Democratization. London: Routledge.

Singh, M. (2011). The "Arab Spring” and beyond (Full Version). http://www.thehindu.com/opinion/op-ed/The-\%E2\%80\%98Arab-Spring\%E2\%80\%99-a nd-beyond-Full-Version/article13369631.ece 
Straaten, I. (2013). Framing Arab Spring. Wageningen University, Wageningen.

Thussu, D. K., \& Freedman, D. (2005). War and the Media: Reporting Conflict 24/7. London: SAGE.

Tuchman, G. (1978). Making News. New York, NY: Free Press.

Vardhan, A. (2017). Global India, Insular Media.

https://www.newslaundry.com/2017/04/11/global-india-insular-media 